Abstracted/indexed in Academic Search Complete, Asia Journals Online, Bangladesh Journals Online, Biological Abstracts, BIOSIS Previews, CAB Abstracts, Current Abstracts, Directory of Open Access Journals, EMBASE/Excerpta Medica, Google Scholar, HINARI (WHO), International Pharmaceutical Abstracts, Open J-gate, Science Citation Index Expanded, SCOPUS and Social Sciences Citation Index;

ISSN: $1991-0088$

\title{
A comparative study on the effect of streptokinase between diabetic and non-diabetic myocardial infarction patients
}

\author{
Md. Anup Rahman Chowdhury', A.K.M. Mosharrof Hossain', Sudhangshu Ranjan Dey², \\ A.K.M. Akhtaruzzaman ${ }^{2}$, and Nur-A-Farhana Islam 3
}

Department of ${ }^{1}$ Pharmacology and ${ }^{2}$ Cardiology, Sylhet M. A. G. Osmani Medical College Hospital, Sylhet 3100 , Bangladesh; ${ }^{3}$ Department of Biochemistry, North East Medical College, Sylhet 3100, Bangladesh.

\begin{tabular}{|c|c|}
\hline Articl & \\
\hline Received: & 28 January 2008 \\
\hline Accepted: & 6 April 2008 \\
\hline Available Online: & 11 April 2008 \\
\hline DOI: $10.3329 /$ bjp. & i1.822 \\
\hline is article: & \\
\hline Chowdhury MA & Hossain AKMI \\
\hline ey SR, Akhtaru & aman AKM, Isla \\
\hline $\begin{array}{l}\text { NAF. A compar } \\
\text { effect of streptok }\end{array}$ & $\begin{array}{l}\text { ve study on th } \\
\text { ase between dis }\end{array}$ \\
\hline & etic myocardi \\
\hline & gladesh J Pha \\
\hline
\end{tabular}

\begin{abstract}
A prospective interventional study was carried out to compare the thrombolytic effect of streptokinase between diabetic and non-diabetic myocardial infarction patients. Out of 187 study subjects with acute ST segment elevation myocardial infarction, admitted at coronary care unit, 126 patients were nondiabetic and 61 patients were diabetic. Streptokinase was administered to all patients. Resolution (reduction) of elevated ST segment was evaluated after 90 min of streptokinase administration. Successful reperfusion ( $\geq 70 \%$ ST-resolution) was significantly higher in non-diabetic than diabetic $(\mathrm{p}<0.001)$, while failed reperfusion ( $<30 \%$ ST resolution) was significantly higher in diabetic patients $(p<0.001)$. It may be concluded that diabetes mellitus might affect the thrombolytic outcome of acute myocardial infarction patients with diabetes mellitus.
\end{abstract}

\section{Introduction}

Acute myocardial infarction may be considered as a potential epidemic for mankind (WHO, 1982). Incidence of coronary disease is increasing in Bangladesh (Khandaker et al., 1986). Death rates from coronary heart disease in UK are among the highest in the world but are falling now (Boon et al., 2002). However, South Asians living in the UK and Canada do not display high rates of smoking, hypertension, or elevated cholesterol but still have higher rates of coronary artery disease compared with Europeans (Yusuf et al., 2001).

The acute coronary syndromes include ST segment elevation myocardial infarction (STEMI), non-ST segment elevation myocardial infarction (NSTEMI), and unstable angina. Diabetes mellitus is one of the six primary risk factors identified for myocardial infarc- tion, others are dyslipidemia, hypertension, smoking, male gender, and family history of atherosclerotic arterial disease. Diabetes is a dyslipidemic disease and increases the rate of atherosclerotic progression of vascular occlusion (Bajzer, 2002). Among patients with an acute myocardial infarction, $10-25 \%$ has diabetes (Mak et al., 1997). Even when promptly receiving thrombolytics the outcome in diabetic subjects is still worse than non-diabetics, manifesting impaired postthrombolysis left ventricular function and prognosis (Zairis et al., 2002)

The aim of thrombolysis in acute myocardial infarction is early and complete myocardial reperfusion. Incomplete or failed reperfusion is associated with an increased risk of death and left ventricular dysfunction. Currently available fibrinolytic agents that dissolve vascular thrombi are: a) Non-selective fibrinolytic agent 
(streptokinase, anistreplase, urokinase) and b) Recombinant tissue-type plasminogen activator (alteplase, duteplase, reteplase).

Streptokinase was the first thrombolytic drug to be described and introduced in the treatment of myocardial infarction since 1958 (Hermentin et al., 2005). However, newer fibrinolytic agents are equivalent but not superior to older non-selective agents (Sabatine et al., 2005).

Use of streptokinase in patients with acute myocardial infarction is considered up to 12 hours after the onset of chest pain (Maxwell, 1999). But it is the $1^{\text {st }}$ hour considered golden hour for thrombolytic therapy. The outcome of acute myocardial infarction treated with fibrinolytic therapy can be evaluated either by coronary angiographic measurement of TIMI (Thrombolysis In Myocardial Infarction) blood flow or by the measurement of ST segment resolution at $90 \mathrm{~min}$ after streptokinase infusion, in 12 lead electrocardiogram (Zairis et al., 2004). Although successful recanalization of the epicardial vessel is a necessary condition, it is the micro -vascular flow that most strongly correlates with outcome. ST-segment changes reflect myocardial rather than epicardial flow and hence yield prognostic information beyond that provided by coronary angiogram alone (Kenner et al., 1995; Van t'Hof et al., 1997; Santoro et al., 1998). ST segment resolution within 90 min is a simple measure of assessing reperfusion in patients receiving fibrinolytics (de Lemos et al., 2000).

Mortality after acute myocardial infarction in patients with diabetes is about twice that of non-diabetic patients (Woodfield et al., 1996). It is uncertain whether this difference in mortality is due to a lower rate of successful thrombolysis, increased re-occlusion after successful thrombolysis, greater ventricular injury or more adverse clinical profile in diabetic patients.

In Bangladesh, $90-95 \%$ of all diabetes patients belong to type 2 diabetes (Mahtab et al., 2003). Current thrombolytic treatment of acute myocardial infarction, derived from large clinical trials has dramatically improved survival in both non-diabetic and diabetic patients. However despite these improvements, diabetes still doubles the fatality rate. As because diabetes profoundly affects cardiovascular disease, one could argue that clinical trial with potential implications for the care of patients with ischemic heart disease, should be specifically designed to evaluate the effect of thrombolytic therapy in diabetic patients. In this study, we evaluated the impact of type 2 diabetes in intravenous thrombolysis effectiveness by using a 12-lead ECG.

\section{Materials and Methods}

This prospective interventional study was carried out during the period of July 2006 to June 2007. The patients, who were admitted in coronary care unit with the diagnosis of ST elevation myocardial infarction, were taken as the study subjects. Initially 199 patients with acute myocardial infarction were selected. Among them, 12 were excluded (7 due to uninterruptible ECG, 5 died during streptokinase therapy). Of the rest 187, 126 patients were non-diabetic and 61 were diabetic.

Inclusion criteria were- patients with STEMI came within 12 hours of chest pain, known diabetic or established during hospital stay by repeated blood glucose estimation. Exclusion criteria were late presentation, after 12 hours of chest pain, type 1 diabetes, IGT, history of previous myocardial infarction.

Streptokinase was given to each patient at a dose of 1.5 million units, diluted in $100 \mathrm{~mL}$ of normal saline, in 1 hour. Informed written consent of the patient/attendant was taken. Fasting plasma glucose was recorded from all patients, in the morning of day following hospital admission. For differentiating new case of diabetes, stress hyperglycemia and non-diabetic, fasting plasma glucose measurements were repeated in stable condition prior to discharge from hospital. Complications like hypotension, shock, hemorrhagic manifestation following streptokinase were noted.

In normal 12-lead ECG, ST segment lies between QRS complex and the ' $\mathrm{T}$ ' wave. The normal ST segment begins at the ' $\mathrm{J}$ ' point, the first point of inflexion on the upstroke of the ' $S$ ' wave and is situated on the isoelectric line- that is at the same level to the part between ' $\mathrm{T}$ ' wave and next ' $\mathrm{P}$ ' wave (Carley et al,. 2002).

Elevation of ST segment occurs during acute myocardial infarction, which returns to the iso-electric line within 48 to 72 hours if not treated with thrombolytics. Reduction of height of ST segment elevation (ST resolution) towards baseline within 90 min after streptokinase infusion has been shown to be a useful predictor of successful reperfusion (Bassand et al., 2005). The STsegment elevation resolution stratified by Schroder et 


\section{Table I}

Baseline characteristics of non-diabetic and diabetic myocardial infarction patients

\begin{tabular}{|c|c|c|}
\hline Variables & $\begin{array}{c}\text { Non-diabetic } \\
\quad(\mathrm{n}=126)\end{array}$ & $\begin{array}{c}\text { Diabetic } \\
(\mathrm{n}=61)\end{array}$ \\
\hline Age $($ mean $\pm \mathrm{SD})$ year & $48.5 \pm 9.1$ & $51.2 \pm 9.7$ \\
\hline Number of male & 115 & 56 \\
\hline Number of female & 11 & 5 \\
\hline Positive smoking history & 97 & 45 \\
\hline Sedentary life style & 67 & 37 \\
\hline Family history of coronary artery disease & 55 & 26 \\
\hline $\mathrm{BMI}($ mean $\pm \mathrm{SD}) \mathrm{kg} / \mathrm{m}^{2}$ & $27.3 \pm 1.2$ & $27.5 \pm 1.1$ \\
\hline Time of thrombolysis after admission (mean \pm SD) hour & $5.68 \pm 1.5$ & $4.87 \pm 2.3$ \\
\hline History of hypertension & 73 & 36 \\
\hline
\end{tabular}

al. (1994) into 3 categories: a) Complete ST resolution ( $\geq 70 \%$ reduction of ST elevation), b) Partial ST resolution ( $<70$ to $30 \%$ reduction of ST elevation), and c) Failed ST resolution ( $<30 \%$ reduction of ST elevation).

Twelve-lead ECG was recorded immediately before start of thrombolytic therapy and at $90 \mathrm{~min}$ thereafter from the patient with ST elevation myocardial infarction. The sum of ST-segment elevation was measured by hand held caliper at $80 \mathrm{~ms}$ (two small squares) beyond the ' $\mathrm{J}$ ' point in leads $\mathrm{I}, \mathrm{aVL}, \mathrm{V}_{1}$ to $\mathrm{V}_{6}$ for anterior, leads II, III, aVF for inferior and lead $V_{1}$ to $V_{4}$ for anteroseptal infarction (Purcell et al., 1997).

The ST-segment elevation resolution was calculated as the initial sum of ST-segment elevation (on pre-treatment ECG) minus the sum of ST-segment elevation on the second ECG (90 min after streptokinase infusion) divided by the initial sum of ST-segment elevation and expressed as percentage (Schroder et al., 1994). Complete ST-resolution ( $\geq 70 \%$ ST-resolution) in patients with acute myocardial infarction, most likely identifies patients with successful reperfusion following streptokinase therapy and these patients proved to be a very low-risk group with good prognosis whereas failed or no ST-resolution $(<30 \% \quad$ ST-resolution) identifies patients with failed myocardial reperfusion, which means that these patients have a higher risk for an adverse outcome. However, partial ST-resolution $(<70$ to $30 \%$ ) is related to impairment of reperfusion at the myocardial level reflecting the unpredictable effect of streptokinase (Yuling et al., 2001; Zeymer et al., 2001).

Twelve-lead ECG was recorded immediately with preformed data collection sheet- 1) by observation, 2) by clinical examination, 3) ECG and 4) biochemical examination (fasting blood glucose). All statistical analyses were done by SPSS version 12 . The $p<0.05$ was taken as level of significance. Unpaired t-test, $\mathrm{Z}$ proportion test and Chi-square test $\left(x^{2}\right)$ were done where applicable.

\section{Results}

Grouping of study subjects, sex distribution, socioeconomic and risk factors characteristics were presented in Table I. Patients of both group were matched in respect to age, sex, socio-economic status and associated risk factors.

Table II shows comparison of ST-resolution at $90 \mathrm{~min}$ after streptokinase between non-diabetic and diabetic myocardial infarction patients where complete ST-resolution occurred in $61(48.4 \%)$ and 12 (19.6\%) patients respectively. The incidence of partial ST-resolution in non-diabetic and diabetic patients was $40(31.7 \%)$ and 8 $(13.1 \%)$ where 25 patients in non-diabetic and 41 patients in diabetic patients showed failed ST resolution. Chi-square $\left(\chi^{2}\right)$ test was done to assess the influence of diabetes on the efficacy of streptokinase, by evaluating difference of ST-resolution between diabetic and non-diabetic subjects. There was significantly reduced ST-resolution observed in diabetic myocardial infarction patient $\left(\chi^{2}=40.7 ; \mathrm{p}<0.001\right)$.

Most commonly reported complications of strepto kinase infusion were reported in Table III. During 
Table II

Comparison of ST resolution between non-diabetic and diabetic patients

\begin{tabular}{|c|c|c|c|c|c|c|}
\hline \multirow[t]{2}{*}{ Group } & \multicolumn{3}{|c|}{ Number of patients showing ST resolution at $90 \mathrm{~min}$ after streptokinase } & \multirow[t]{2}{*}{ Total } & \multirow[t]{2}{*}{ Chi value } & \multirow[t]{2}{*}{$\mathrm{p}$ value } \\
\hline & Complete & Partial & Failed & & & \\
\hline Non-diabetic & 61 & 40 & 25 & 126 & 40.7 & $<0.001$ \\
\hline Diabetic & 12 & 8 & 41 & 61 & 40.7 & $<0.001$ \\
\hline Total & 73 & 48 & 66 & 187 & & \\
\hline
\end{tabular}

Table III

Streptokinase infusion related complications in non-diabetic and diabetic patients

\begin{tabular}{|lccc|}
\hline Complications & $\begin{array}{c}\text { Non-diabetic patients } \\
(\mathrm{n}=126)\end{array}$ & $\begin{array}{c}\text { Diabetic patients } \\
(\mathrm{n}=61)\end{array}$ & $\mathrm{p}$ value \\
\hline Hypotension & 34 & 18 & 0.319 \\
Shock & 8 & 7 & 0.268 \\
Hemorrhagic manifestation & 6 & 5 & 0.341 \\
\hline
\end{tabular}

hospital stay, among the notable complications, hypotension was observed in $34(27.0 \%)$ and $18(29.6 \%)$ patients, shock in $8(8.7 \%)$ and $7(11.4 \%)$, hemorrhagic manifestation was noted in $6(4.8 \%)$ and $5(8.2 \%)$ nondiabetic and diabetic myocardial infarction patients respectively.

\section{Discussion}

Intravenous streptokinase during acute myocardial infarction is a well recognized and effective treatment, which has beneficial effects on cardiovascular event related mortality. Conceptually, therapeutic intervention for STEMI must minimize cell death by interruptting the ongoing process of infarction and attempt to reverse the ischemic metabolic derangement of still viable cells. The aim of thrombolysis in acute myocardial infarction is early and complete reperfusion. Incomplete or delayed reperfusion is associated with an increased risk of death and left ventricular dysfunction. The time to reperfusion and complete reperfusion remain the key determinants for fibrinolysis. ST-segment recovery over serial ECG's in STEMI represents both reversal of ischemia and interruption of the infarction.

Among risk factors for coronary artery disease, diabetes is a major contributor, not only to the development of coronary artery disease but also to outcome following various manifestations of the disease (Norhammer et al., 2004).

Several studies have reported similar angiographic (Angeja et al., 2002; Woodfield et al., 1996) or ECG (Mak et al., 1997; Ishihara et al., 2001) success in both type 2 diabetic and non-diabetic subjects, while others have shown that the diabetics have less complete resolution of ST elevation than the non-diabetics (Angeja et al., 2002; Zairis et al., 2004). To evaluate this issue, it has been hypothesized that type 2 diabetes might interfere with intravenous thrombolysis effectiveness, as estimated by angiographic or ECG criteria. The purpose of this study was to assess the thrombolytic effect of streptokinase in type 2 diabetic myocardial infarction patients by using 12-lead ECG and to compare with the non-diabetic myocardial infarction patient in the same setting.

In a recent comparative study of ST-segment resolution by thrombolytic versus primary coronary intervention (PCI), showed the resolution of ST-segment by thrombolytic are as follows: Complete $51.9 \%$, partial $26.6 \%$ and failed resolution in $21.5 \%$ acute myocardial infarction patients after $90 \mathrm{~min}$ of initiation of fibrinolytic therapy (Thiele et al., 2005). By using the same resolution criteria, in our study we observed the similar results in non-diabetic myocardial infarction where $48.4 \%$ patients showed complete resolution, 31.7\% patient's partial resolution and $19.8 \%$ showed failed 
resolution. But in case of diabetic myocardial infarction, $19.7 \%$ patients showed complete resolution, $13.1 \%$ partial resolution and $67.2 \%$ showed failed resolution.

In our study, more 'complete ST-resolution' was seen in non-diabetic patient (48.4 vs. $19.7 \% ; Z=4.25 ; \mathrm{p}<0.001$ ) whereas type 2 diabetic subjects were presented with significantly higher incidence of failed ST-resolution than non-diabetic subjects (67.2 vs. $19.8 \% ; Z=6.79$; $\mathrm{p}<0.001)$. This significant change in ST-resolution between non-diabetic and diabetic group was similar with the study done by Zairis et al., 2004, who showed significant difference between diabetic and non-diabetic patient in relation to complete ( 34.1 vs. $68.2 \%$; $<<0.001$ ) and incomplete $(65.9$ vs. $31.8 \%$; $<<0.001)$ resolution.

In comparison between two groups, significantly reduced ST-resolution was observed in diabetic patients $\left(\chi^{2}=40.69, \mathrm{p}<0.001\right)$. Our results are consistent with a published meta-analysis in which it was shown that type 2 diabetic subjects had less ST resolution after intravenous thrombolysis administration compared with non-diabetic subjects (Angeja et al., 2002). Furthermore, certain altered properties of cellular component of blood (McDonagh et al., 1997) are also likely to enhance the potential of accumulating in the microcirculation of the heart, causing further danger by an oxygen radical-mediated inflammatory process.

Stress hyperglycemia has a detrimental effect on thrombolytic outcome after acute myocardial infarction. Mortality may increase, especially in non-diabetic patients. Diabetes can be differentiated from stress hyperglycemia with certainty only after the acute phase of the infarction. Thus, any attempt to identify undiagnosed diabetes in our study would have been biased because patients must survive the acute phase to be diagnosed.

Adjunctive therapies such as aspirin have been found to be important to reduce mortality in myocardial infarction. Administration of aspirin just prior to streptokinase infusion in our study patients may have contribution somewhat to the overall success rate of streptokinase efficacy but certainly not influence the relative success/failure rates in each time segment.

Anaphylaxis and intracranial hemorrhage are the most serious complications of the streptokinase therapy. In the present study hypotension was the major complication in non-diabetic and diabetic patient (27.0 vs. $29.6 \%$ ) while hemorrhage was least (4.8 vs. $8.2 \%$ ).

In our study it was proved that reperfusion failed in a significant proportion of diabetic patient with STEMI in comparison with non-diabetic persons (67.2 vs. 19.8\%). These finding reinforces the need for increased efforts to discover newer pharmacological agents to reduce failed reperfusion after streptokinase therapy in diabetic patients with myocardial infarction. To further improve outcome after myocardial infarction and thrombolysis among patients with diabetes, newer strategies such as peri-infarction metabolic control and primary angioplasty should be investigated.

\section{Conclusion}

The present results emphasize that, despite the established benefit of fibrinolytic therapy in acute myocardial infarction, a significant proportion of diabetic patients do not achieve complete reperfusion within $90 \mathrm{~min}$ of starting thrombolytic therapy. So, due attention is required for the better management of diabetic myocardial infarction patients. This should, however, be supplemented with further therapies and strategies directed towards the many abnormalities that are associated with diabetes, such as endothelial dysfunction, dysglycemia and coagulation and fibrinolytic disturbances. Key targets for additional treatment need to be explored in forthcoming trials in diabetic patients with and without revascularization.

\section{References}

Angeja BG, De Lemos J, Murphy SA, Marble SJ, Antman EM, Cannon $\mathrm{CP}$, et al. Thrombolysis in myocardial infarction: Impact of diabetes mellitus on epicardial and microvascular flow after fibrinolytic therapy. Am Heart J. 2002; 144: 649-56.

Bajzer CT. Acute myocardial infarction. In: Medicine index. Cleveland Clinic Foundation, 2002, pp 222-26.

Bassand JP, Danchin N, Filippatos G, Gitt A, Hamm C, Silber $S$, et al. Implantation of reperfusion therapy in acute myocardial infarction: A policy statement from the european society of cardiogy. Eur Heart J. 2005; 26: 2733-41.

Boon MA, Fox KAA, Bloomfield P. Bradbury A. Cardiovascular disease. In: Davidson's Principles and practice of 
medicine. Haslett C, Chilvers ER, Colledge NR (eds). 19th ed. London, Churchill Livingstone, 2002, pp 357-482.

Carley SD, Gamon R, Driscoll PA, Brown G, Wallman P. What's the point of ST elevation? Emerg Med J. 2002; 19: 12628.

Hermentin P, Cuesta-Linker T, Weisse J, Heinz Schmidt K, Knorst M, Scheld M, et al. Comparative analysis of the activity and content of different streptokinase preparations. Eur Heart J. 2005; 26: 933-40.

Ishihara M, Sato H, Kawagoue T, Shimatani $\mathrm{Y}$, Kurisu S, Nishioka $K$, et al. Impact of diabetes mellitus on long-term survival after acute myocardial infarction in patients with single vessel disease. Heart 2001; 86: 133-38.

Kenner MD, Zajec EJ, Kondos GT, Dave R, Winkelmann JW, Joftus J, et al. Ability of the no-reflow phenomenon during an acute myocardial infarction to predict left ventricular dysfunction at one month follow-up. Circulation 1995; 76: 861-68.

Khandaker RK, Hossain D, Hossain M, Zaman S. Retrospective analysis of acute myocardial infarction: A 4 year study of 2690 patients. Bangladesh Heart J. 1986; 1: 14-17.

McDonagh PF, Hokama JY, Copeland JG, Reynolds JM. The blood contribution to early myocardial reperfusion injury is amplified in diabetes. Diabetes 1997; 46: 1859-67.

Mahtab H, Khan AR, Latif ZA, Pathan F, Ahmed T. Guidelines for care of type 2 diabetes mellitus in Bangladesh. BIRDEM Clinical Research Group. 2003.

Mak KH, Moliterno DJ, Granger CB, Miller DP, White HD, Wilcox HD, et al. Influence of diabetes mellitus on clinical outcome in the thrombolytic era of acute myocardial infarction. J Am Coll Cardiol. 1997; 30: 171-79. http:// dx.doi .org/10.1016/S0735-1097(97)00118-6

Maxwell S. Emergency management of acute myocardial infarction. Br J Clin Pharmacol. 1999; 48: 284. http:// dx.doi.org/10.1046/j.1365-2125.1999.00998.x

Norhammar A, Malmberg K, Diderholm E, Lagerqvist B, Lindahl B, Ryden L, et al. Diabetes mellitus: The major risk factor in unstable coronary artery disease even after consideration of the extent of coronary artery disease and benefits of revascularization. J Am Coll Cardiol. 2004; 43: 585 -91. http:/ / dx.doi.org/10.1016/j.jacc.2003.08.050

Sabatine MS, Cannon CP, Gibson CM, Lopez-sendon JL, Montalescot G, Theroux $P$, et al. Addition of clopidegrol to aspirin and fibrinolytic therapy for myocardial infarction with ST-segment elevation. New Engl J Med. 2005; 352: 117989. http:// dx.doi.org/10.1056/NEJMoa050522
Purcell IF, Newell N, Farrer M. Change in ST segment elevation 60 minutes after thrombolytic initiation predicts clinical outcome as accurately as later electrocardiographic changes. Heart 1997; 78: 465-71.

Schroder R, Dissmann R, Bruggemann T, Wegscheider K, Linderer T, Tebbe $\mathrm{U}$, et al. Extent of early ST segment elevation resolution: A simple but strong predictor of outcome in patients with acute myocardial infarction. J Am Coll Cardiol. 1994; 24: 384-91.

Thiele H, Engelmann L, Elsner K, Kappl MJ, Storch WH, Rahimi K, et al. Comparison of pre-hospital combinationfibrinolysis plus facilitated percutaneous coronary intervention in acute myocardial infarction. Eur Heart J. 2005; 26: 1956-63. http://dx.doi.org/10.1093/eurheartj/ ehi432

Van t'Hof AW, Liem A, de Boer MJ, Zijlstra F. Clinical value of 12 lead electrocardiogram after successful reperfusion therapy for acute myocardial infarction: Zwolle Myocardial Infarction Study Group. Circulation 1997; 350: 615-19.

WHO Expert Committee. Prevention of coronary heart diseases. WHO Technical report. 1982, Series No. 678. Woodfield SL, Lundergan CF, Reiner JS, Greenhouse SW, Thompson MA, Rohrbeck SC, et al. Angiographic findings and outcome in diabetic patients treated with thrombolytic therapy for acute myocardial infarction: The GUSTO-I experience. J Am Coll Cardiol. 1996; 28: 1661-69. http:// dx.doi.org/10.1016/S0735-1097(96)00397-X

Yuling F, Goodman S, Chang WC, Van de Werf F, Granger CB, Armstrong PW. Time to treatment influences the impact of ST-segment resolution on one-year prognosis: Insights from the assessment of the safety and efficacy of a new thrombolytic (ASSENT-2) trial. Circulation 2001; 104: 2653 59. http://dx.doi.org/10.1161/hc4701.099731

Yusuf S, Reddy S, Ounpuu S, Anand S. Global burden of cardiovascular disease by specific ethnic groups and geographic regions and prevention strategies. Circulation 2001; 104: 2855-64. http://dx.doi.org/10.1161/hc4701.099488

Zairis MN, Lyrus AG, Makrygiannis SS, Psarogianni PK, Adamopoulou EN, Handanis SM. Type 2 diabetes and intravenous thrombolysis outcome in the setting of ST elevation myocardial infarction. Diabetes Care 2004; 27: 96771. http:/ / dx.doi.org/10.2337/ diacare.27.4.967

Zairis MN, Makrygiannis SS, Papadaki OA, Lyras AG, Kouzanidis JP, Ampartzidou OS, et al. Diabetes and ST elevation myocardial infarction. Diabetes Care 2002; 25: 1890 $-91$.

Zeymer U, Schröder R, Tebbe U, Molhoek GP, Wegscheider K, Neuhaus KL. Non-invasive detection of early infarct vessel 
patency by resolution of ST-segment elevation in patients with thrombolysis for acute myocardial infarction: Results of the angiographic substudy of the Hirudin for Improvement of Thrombolysis (HIT)-4 trial. Eur Heart J. 2001; 22: 769-75. http://dx.doi.org/10.1053/euhj.2000.2290

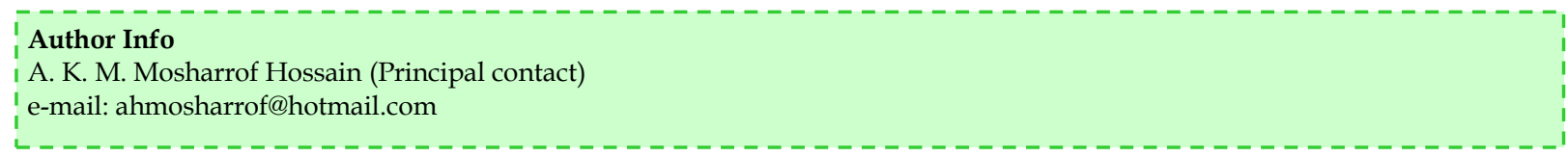

